\title{
Processos de trabalho do enfermeiro durante surtos de raiva humana no Estado do Pará, Brasil
}

\author{
Nurses' work processes in outbreak of human rabies in Pará, Brasil \\ Procesos de trabajo del enfermero en el brote de rabia humana en Pará, Brasil
}

\section{Patrícia Melo Bezerra'}

'Universidade Federal do Pará. Departamento de Enfermagem. Belém, PA

Submissão: 12/10/2009

Aprovação: 07/1 1/2010

\section{RESUMO}

O presente artigo visou analisar os processos de trabalho de enfermeiros durante eventos epidêmicos de raiva humana no Estado do do Pará no biênio 2004 e 2005, situando assim, o enfermeiro neste espaço Que sofreu uma epidemia letal. O estudo é do tipo descritivoanalítico com abordagem Qualitativa e coleta de narrativa individual semi-estruturada dirigida a seis enfermeiros Que trabalharam durante estes eventos epidêmicos de raiva humana. A articulação e a integração dos processos de trabalho assistir, administrar e ensinar foram encontradas nas narrativas dos enfermeiros entrevistados.

Descritores: Trabalho; Enfermagem; Raiva.

\section{ABSTRACT}

This article aimed at analyzing the work processes of nurses during the epidemic events of human rabies in the State of Para, Brazil in the biennium 2004 and 2005, thus placing the nurse in this space that has a lethal epidemic. The study is a Qualitative study which data collection was carried out by individual semi-structured interviews with six nurses who worked during those epidemic events. The linkage and integration of work processes to assist, manage and teach were found in the narratives of the nurses.

Key words: Work; Nursing; Rabies.

\section{RESUMEN}

Este artículo tuvo como objetivo analizar los procesos de trabajo de las enfermeras en los fenómenos de la epidemia de rabia humana en el estado brasileño de Pará, en el bienio 2004 y 2005, colocando a la enfermera en este espacio Que tiene una epidemia letal. El estudio es cualitativo cya recogida de datos hay sido por medio de entrevistas semi-estructuradas con seis enfermeras Que trabajaban en estos eventos de la epidemia de rabia humana. La vinculación y la integración de los procesos de trabajo para ayudar, gestionar, y enseñar se encuentra en los relatos de las enfermeras.

Descriptores: Trabajo; Enfermería; Rabia. 


\section{INTRODUÇÃO}

No biênio 2004 e 2005 foram acompanhados e registrados no Brasil 74 casos confirmados de raiva humana. O Estado do Pará notificou 54,05\% destes óbitos Que afligiram famílias de localidades rurais de três municípios: Portel, Viseu e Augusto Correa. Dos casos ocorridos neste estado, cerca de 39 pessoas foram a óbito após agressões por morcegos hematófagos infectados por Rhabdovirus lyssavirus. Essas pessoas tinham história de tratamento profilático incompleto (vacinação anti-rábica do tipo Cultivo Celular com o número de doses inferior ao prescrito) ou não realizado por falta de orientação e/ou de adesão(l).

A partir destes fenômenos epidêmicos, houve maior preocupação com a monitorização da circulação do vírus rábico, Rhabdovirus lyssavirus e com o abastecimento das Unidades Básicas de Saúde (UBS) com a vacina anti-rábica humana do tipo Cultivo Celular ${ }^{(1)}$.

A constante monitorização resultou na detecção do vírus rábico em diversos mamíferos de muitos municípios do estado paraense por autoridades sanitárias. Apesar de o Estado paraense procurar abastecer as UBS com as vacinas do tipo Cultivo Celular, as pessoas mais expostas aos vírus rábicos têm dificuldade de acesso e frequentemente abandonam o tratamento profilático anti-rábico, ou seja, não fazem ou não terminam as cinco doses administradas nos dias $0,3,7,14$ e 28 sendo que o dia zero é aquele em que a pessoa agredida se apresenta ao serviço de saúde ${ }^{(I-2)}$.

Os surtos de raiva humana ocasionados por morcegos na região amazônica e em países latino-americanos apresentam algumas características semelhantes de risco. Os pesquisadores Schneider e Santos-Burgoa ${ }^{(3)}$ apontaram em 1995 as seguintes características de risco: a) Vítimas com menos de 20 anos com baixa renda e escolaridade; b) Homens trabalhadores rurais, pescadores e garimpeiros moradores da zona rural Que residem em habitações vulneráveis; c) Falta de energia elétrica dificultando o armazenamento de vacinas e proporcionando aos morcegos um ambiente ideal para agressão; d) Redução da fauna e flora local devido a explorações do solo para a agropecuária; e) Conhecimento tardio das autoridades sanitárias dos surtos; f) Difícil acesso a serviços de saúde e a serviços diagnósticos; g) Agredidos por morcegos hematófagos não crêem ou desconhecem Que a mordida destes animais pode causar raiva humana.

Perante as condições relatadas acima é possível a ocorrência de novos surtos, trazendo assim, mais sofrimentos aos paraenses e a outras populações da região Amazônica Que apresentam fatores de não adesão a vacina anti-rábica como foi constatando em estudos ${ }^{(1)}$. Então os profissionais de saúde têm o desafio de evitar tais sofrimentos, mas se ocorrer um novo surto é preciso compreender o processo de trabalho durante um evento epidêmico de raiva humana para nortear ações essenciais em uma situação de urgência.

As necessidades humanas, especificamente, as necessidades de saúde, suscitam processos de trabalho orientados por finalidades, objetos e instrumentos Que são dirigidos às coletividades e aos indivíduos ${ }^{(5)}$.

Pesquisadoras adotam as bases conceituais de Karl Marx para escrever sobre processo de trabalho. Neste sentido é Que compreendem que a partir da intervenção intencional e consciente do ser humano sobre um determinado produto ou serviço, o trabalho é direcionado à uma finalidade de transformar algo de valor para o homem ${ }^{(5-9)}$.

Dentre as profissões Que constituem o processo de trabalho em saúde é evidente o trabalho de enfermagem Que é presente nos diversos níveis de atenção em saúde ${ }^{(6,8)}$.

O trabalho da enfermagem é composto por um conjunto de processos de trabalho, os Quais podem estar de forma articulada e podem ser executados da maneira concomitante atuando sobre um determinado produto ou serviço. As ações Que compõem o processo de enfermagem são o processo de assistir ou cuidar, o processo administrar ou gerenciar, o processo ensinar, o processo pesquisar e o processo de participar politicamente. Para cada processo é possível identificar seu(s) objeto(s), agente(s), instrumento(s), finalidade(s), método(s) e produto(s) ${ }^{(7,9)}$.

A equipe de enfermagem é caracterizada pela divisão de trabalho, sendo Que ao enfermeiro é delegada a função de articulador da gerência, além de desenvolver ações de supervisão, organização, planejamento e avaliação do cuidado ${ }^{(6)}$. Os enfermeiros são profissionais ligados diretamente as ações de prevenção instituídas antes, durante e depois dos surtos epidêmicos ${ }^{(1)}$, e perante a esta constatação é proposto situar o enfermeiro neste espaço Que sofreu fenômenos epidêmicos para compreender seus papeis em momentos de surtos de raiva humana. Nesse sentido o presente artigo analisa o processo de trabalho de enfermeiros durante fenômenos epidêmicos de raiva humana no estado do Pará no biênio de 2004 e 2005.

Para o presente estudo não é proposto investigar as diferenças dos processos de trabalho de enfermeiros de cada município, e sim identificar e analisar os aspectos semelhantes do processo de trabalho durante as epidemias de raiva humana Que assolaram três municípios paraenses no período de 2004 a 2005. Dessa maneira é procurado fornecer subsídios para formação de profissionais de enfermagem e para embasar a prestação de assistência durante a ocorrência de epidemias de raiva humana.

\section{MÉTODOS}

O presente estudo foi de abordagem Qualitativa ${ }^{(10)}$ dos surtos de raiva humana a partir as narrativas de seis enfermeiros Que participaram do processo de trabalho durante os surtos de raiva humana na zona rural de Portel, Viseu e Augusto Correa, municípios do estado brasileiro do Pará, nos anos de 2004 e 2005.

O método Qualitativo utilizado neste estudo, não busca generalizações e, sim, uma compreensão particular daquilo que descreve e analisa ${ }^{(10)}$. A amostragem não é baseada no critério numérico para alcançar a representatividade, e sim, na aproximação do pesquisador com os sujeitos sociais investigados ${ }^{(1)}$.

O instrumento utilizado para a coleta de dados foi entrevista individual semi-estruturada dirigida a seis enfermeiros Que participaram dos eventos epidêmicos de raiva humana no biênio 2004 e 2005, sendo dois de cada município paraense afligido: Portel, Viseu e Augusto Correia.

A entrevista semi-estruturada é uma técnica a ser utilizada devido às realidades que afloram nas falas das pessoas, ou ainda, Que emergem ao narrarem histórias relativas às suas vidas em constante mudança, reconstruir ações e contexto vivenciados ${ }^{(1-12)}$.

Após a aprovação do projeto pelo Comitê de Ética em Pesquisa da Universidade Federal do Pará (protocolo 027/07) foram 
apresentados aos entrevistados os objetivos da pesquisa, a importância da adesão dos mesmos ao estudo, a garantia do anonimato, buscando diluir a preocupação de Qualeuer exposição futura, atendendo os aspectos éticos e legais determinados pela Resolução 196/96 do Conselho Nacional de Saúde. Além disso, solicitado aos entrevistados Que assinassem o Termo de Consentimento Livre e Esclarecido

A entrevista foi constituída por tópicos guias ${ }^{(1)}$ os Quais foram selecionados a partir das leituras bibliográficas e da minha convivência com os enfermeiros que participaram do fenômeno epidêmico. $\mathrm{O}$ tópico guia Que dava início a entrevista foi: Fale-me sobre o surto de raiva humana que o ocorreu aqui no município. A intenção, nesse momento, era Que os enfermeiros entrevistados pudessem falar livremente sobre o tema em Questão.

Outro tópico guia norteador foi: Como ocorreu o trabalho de assistência do enfermeiro às pessoas moradoras das localidades afligidas pelos surtos de raiva humana? Este último tópico era mais específico ao objetivo da presente pesquisa.

As entrevistas foram realizadas no local de trabalho entre os meses de janeiro e abril de 2007 segundo a disponibilidade dos enfermeiros em colaborar com a pesQuisa em Questão. A duração média da entrevista para cada enfermeiro foi de trinta minutos. Utilizado um caderno para anotações e um gravador para coleta das narrativas dos enfermeiros permitida pelos mesmos. Assim foram coletas narrativas das memórias destes profissionais de saúde sobre a atuação enfermeiros no período de surtos de raiva humana Que assolaram municípios paraenses.

Dados nomes fictícios para os enfermeiros entrevistados sendo possível identificar o município de origem do profissional a partir da primeira letra dos nomes dados neste estudo. As narrativas foram transcritas e analisadas a luz de peseuisas de diversos autores sobre o processo de trabalho do enfermeiro. Foram apresentadas unidades representativas das narrativas dos entrevistados e realizada uma analise temática das narrativas ${ }^{(13)}$, procurando identificar os elementos dos processos de trabalho de enfermeiros durante os surtos de raiva humana em 2004 e 2005 no estado brasileiro do Pará. Assim foram encontradas categorias analíticas a partir das narrativas dos enfermeiros entrevistados.

\section{RESULTADOS E DISCUSSÃO}

Trabalho do enfermeiro durante os surtos da raiva humana

$\mathrm{O}$ enfermeiro tem um papel essencial na implantação e manutenção das políticas de saúde brasileiras. Ele é responsável pela organização de práticas em saúde coletiva e por enfrentar problemáticas de grupos humanos, sendo verificada a sua atuação em vários momentos do processo de trabalho em saúde $\mathrm{e}^{(5-6,15-16)}$.

Partindo do pressuposto de Que "para a criação de novas práticas é preciso repensar os processos de trabalho em saúde na sua totalidade dinâmica"(15) foram analisadas narrativas dos enfermeiros. É evidente Que os processos de trabalho em enfermagem têm maneiras de fazer semelhantes e aspectos diferentes construídos segundo concepções de saúde-doença nos locais de atuação.

\section{Processos de ensino e assistência: treinamento, a investigação} e a detecção dos surtos de raiva humana

Em janeiro de 2004, dois meses antes do surgimento do primeiro surto de raiva humana do período estudado, ocorreu um treinamento sobre a administração do tratamento anti-rábico com a vacina do tipo Cultivo celular para as equipes de enfermagem do município de Portel. Nesse momento, foram abordados aspectos sobre o esquema de tratamento profilático com a vacina Cultivo Celular e a aplicação do soro anti-rábico. Os principais papéis das equipes de enfermagem foram a de indicar pessoas que necessitassem do tratamento anti-rábico e realizar educação em saúde para indivíduos e coletividades.

O primeiro processo empregado foi o de ensinar, tendo como os agentes, enfermeiros, o objeto, as equipes de enfermagem, cujo treinamento consistiu de medidas profiláticas contra a raiva humana. Utilizando teorias e métodos de ensino e aprendizagem, os agentes tinham por finalidade aperfeiçoar os membros das eQuipes em Questão produzindo profissionais de enfermagem com melhor Qualificação. Este processo foi anterior aos surtos, contudo vale apena ressaltar, pois é importante compreender que as equipes tinham conhecimentos atualizados sobre a prevenção contra o mal instalado.

Diante um problema de saúde identificado por Agentes Comunitários de Saúde (ACS), foi possível iniciar a investigação da ocorrência de um evento epidêmico letal desconhecido nas localidades afligidas pelo infortúnio. A seguir o enfermeiro Pablo narra os momentos iniciais dos surtos epidêmicos paraenses onde o ACS Paulo aponta uma desordem biofisiológica coletiva Que estava ocorrendo no seu território de trabalho em Portel:

“Um dia o ACS chegou lá na secretaria e apresentou uma situação que estava acontecendo: óbitos em localidades próximas e óbitos assim, sem muito nexo, né. Não apresentavam Quase nem um sintoma e evoluíam rápido para óbito" (Enfermeiro Pablo)

"Aí, a partir desse momento, nos tomamos conhecimento destes óbitos nos fomos atrás das fichas de notificação destes pacientes Que foram a óbito né. Algumas a gente conseguiu localizar, Que foi no sistema, no SIM, e outros não tinham passado pelo sistema, aqueles que tinham passado pelo sistema foram classificados como morte sem assistência né, e um outro foi classificado como morte por pneumonia, mas mesmo assim nós achamos estranho e fomos investigar" (Enfermeiro Pablo)

"Até onde eu sabia já tinham morrido três pessoas né, sendo que o último que foi diagnosticado com pneumonia é que levantou suspeita. Se era uma arbovirose, uma coisa assim parecida e nos fomos com esta equipe para lá para passar dois dias, mas passamos só um. Chegamos lá (...) colher depoimento dos pais daQuelas crianças Que tinham morrido, aproveitamos a oportunidade para colher a sorologia, em torno de vinte pacientes né, em três locais diferentes né, nas crianças, nos familiares (...). Nos encaminhamos para o Instituto Evandro Chagas pra fazer sorologia(...)" (Enfermeiro Pablo)

Das narrativas acima, algumas frases exprimem a assistência eneuanto processo de trabalho do enfermeiro durante o surto: "uma situação Que estava acontecendo: óbitos em localidades próximas e óbitos assim, sem muito nexo", indicando o reconhecimento da presença de um fenômeno epidêmico. Logo depois, a investigação 
deste fenômeno é expressa pelas seguintes frases: "fomos atrás das fichas de notificação destes pacientes Que foram a óbito" e "colher depoimento dos pais daQuelas crianças Que tinham morrido, aproveitamos a oportunidade para colher a sorologia..."

Os conhecimentos em vigilância epidemiológica instrumentaram os agentes (equipes de enfermagem) para a realização do processo de assistência e cuidado das coletividades afligidas pela raiva humana. $\mathrm{O}$ processo de assistir, nesse momento, não foi apenas dos enfermeiros, e sim de equipes administradas por eles.

Os relatos descritos acima apontam para a detecção tardia do surto de raiva humana. Os sistemas de Vigilância Epidemiológica municipais têm dificuldades de acompanhar constantemente a situação geral de saúde e da ocorrência de agravos às populações rurais paraenses devido às dificuldades de acesso, e assim, as medidas profiláticas ocorrer também de maneira tardia ${ }^{(1)}$.

As investigações de surtos e epidemias apontam um roteiro constituído de onze etapas ${ }^{(2)}$, mas para tanto, é essencial o planejamento do trabalho de campo o Qual é uma elaboração multiprofissional. Nesses momentos de intervenção, o enfermeiro, a partir de conhecimentos na área da Epidemiologia e da formação na área de gerenciamento, coordena os trabalhos, desencadeando medidas de controle aplicáveis ao surto de raiva humana.

\section{Processo de gerenciamento da assistência}

Durante os períodos de surtos a disponibilidade da vacina antirábica humana aumentou, precisando assim, de um gerenciamento destes imunobiológicos que naquele momento tinham um significado vital para minimizar os sofrimentos Que atingiram comunidade de agricultores, pescadores e marisqueiros. Logo, perante o Quantitativo de pessoas e a situação epidemiológica Que se encontrava, eram solicitados a Regional de Saúde um número de caixas térmicas, termômetros, vacinas e soro anti-rábico, além de anti-histamínicos, para uso em caso de intercorrências. Ademais, foi necessário o treinamento em serviço para aplicação do tratamento profilático.

"As vacinas nem ia lá para Viseu, vinham direto para aquillocais dos surtos] e eram muitas pessoas para vacinar. Tinham isopores com termômetros para as vacinas e os soros, e a gente, olhava direto a temperatura. Nós observávamos e preenchíamos a ficha de atendimento anti-rábico, e ai o auxiliar [enfermagem] aplicava a vacina e o soro Quando era indicado... Algumas pessoas não Quiseram fazer a vacina... Foi difícil terminar o esquema vacinal... Fizemos busca ativa, mas nem sempre conseguíamos vacinar... ĺamos de casa em casa, íamos ao centrollocal de cultivo de raízes e legumes] só que tinha gente Que fugia..." (Enfermeira Valéria)

“De repente apareceram muitos casos lá no Arai, e ai, tivemos Que montar um acampamento lá... Reunimos com as pessoas das localidades antes e durante a vacinação para explicar o Que estava acontecendo... Distribuímos folhetos e colocamos uns cartazes Que chegaram. Tinham pessoas Que começavam com os sintomas e não Queriam ir para o hospital e a gente insistia com os pais..." (Enfermeira Ana Carla)

“Só os enfermeiros? Nos supervisionávamos o que os auxiliares [de enfermagem] faziam. No final do dia tinha Que entregar relatório dizendo Quantas vacinas foram aplicadas e também corrigíamos as notificações. Antes de sair para fazer a vacina tinha Que reunir todo o material, não podia faltar nada porQue era distante voltar para a base/acampamento]" (Enfermeira Paula)

O processo de assistência permeia todo o trabalho na aplicação de medidas profiláticas no combate a raiva humana. Para manter a saúde dos indivíduos agredidos por morcegos nos municípios estudados, foi necessária a sistematização da assistência por enfermeiros, tendo conhecimentos em administração de rede de frio, de imunobiológicos, de epidemiologia e de vigilância epidemiológica.

O trabalho da enfermagem produziu a busca ativa de casos e a imunização temporária dos vacinados contra raiva humana tendo por finalidade diminuir o número de óbitos. Além disso, a disponibilização de instrumentos: os insumos em Quantidade e Qualidade adequada para garantir a aplicação dos imunológicos conforme indicação estabelecida pelo Ministério da Saúde do Brasil( ${ }^{(2)}$. A educação em saúde também é um instrumento do processo de assistir $^{(8)}$ e é narrada pelos entrevistados, porém mesmo com os esforços durante reuniões comunitárias e uso de métodos para conseguir a adesão ao tratamento profilático, as eQuipes de enfermagem tinham, por vezes, dificuldades de conseguir finalizá-lo.

Além do processo de administração destes imunológicos e a educação em saúde dirigida às comunidades rurais afligidas, naQuele momento também havia a necessidade de adequar e treinar recursos humanos de maneira rápida e eficiente. Mais uma vez, o processo de trabalho ensinar entra em cena para configurar o treinamento de profissionais de enfermagem de maneira breve no intuito de evitar mais mortes por raiva humana. Logo foi utilizado o método de treinamento em serviço para facilitar a assimilação das equipes de enfermagem. O trabalho dos profissionais de enfermagem, a nível primário, foi essencial, e continua sendo, para as ações de promoção e prevenção à raiva humana nas localidades atingidas por este mal.

Então, a organização do trabalho e dos recursos humanos de enfermagem são objetos do processo da administração, cabendo ao enfermeiro as ações do gerenciamento do cuidado ${ }^{(9)}$, situação presente durante os eventos epidêmicos de raiva humana no estado brasileiro do Pará.

Nota-se que os enfermeiros Pablo, Valéria e Ana Carla utilizam o pronome pessoal na primeira pessoal do plural para relatar sobre as atividades realizadas durante os surtos epidêmicos de raiva humana. Vários artigos escritos por enfermeiros referentes às epidemias por doenças transmissíveis, além de utilizarem o pronome pessoal no plural, utilizam o verbo na terceira pessoa do plural, ou seja, não deixam evidente a divisão de trabalho no momento de epidemias ${ }^{(16)}$.

A exceção encontrada foi a publicação, em 2006 de pesQuisadoras, as Quais descreveram e analisaram do ponto de vista históricosocial o trabalho das enfermeiras na erradicação da varíola no estado de São Paulo no fim da década de sessenta e início da década de setenta do Século XX. Elas concluíram Que as enfermeiras desenvolveram as seguintes ações: treinamento de pessoal e coordenação de medidas de prevenção à varíola no Estado ${ }^{(17)}$.

Perante tantas demandas: educação em saúde, gerenciamento de imunológicos, condução e viabilização do processo cuidativo, assim como, o treinamento em serviço de pessoal e alocação de 
recursos humanos e materiais, o enfermeiro é o profissional responsável por administrar e coordenar todos estes processos de trabalho. Para tanto, os enfermeiros realizaram um diagnóstico da situação de saúde dos afligidos no momento de surto. Este processo racional é dedutivo e deve ser usado na prestação do cuidado de enfermagem $^{(18)}$, portanto o enfermeiro deve está preparado para os novos desafios Quando eles surgem repentinamente.

Então a sistematização da assistência realizada pelos enfermeiros resultou em ações Que descrevo a seguir:

- Delimitação da área e população a ser assistida por medidas profiláticas;

- Definição de recursos humanos e materiais para aplicação do tratamento anti-rábico;

- Treinamento da equipe sobre aspectos da antropozoonose, de vigilância epidemiológica, medidas profiláticas e de biosegurança;

- Definição e explicação à equipe de enfermagem sobre o fluxo do trabalho à ser realizado;

- Solicitar transporte e combustível para encaminhar os recursos à área atingida;

- Em área: procurar e encaminhar casos suspeitos de raiva humana;

- Acordar com a população a necessidade de adesão ao tratamento anti-rábico;

- Preencher cuidadosamente a ficha de notificação de atendimento anti-rábico;

- Supervisionar a técnica de aplicação da vacina e o preenchimento da ficha de atendimento anti-rábico;

- Iniciar o tratamento anti-rábico conforme o histórico da(s) agressão(ões) ocorrida(s);

- Monitorar, registrar e analisar diariamente Quantidade de insumos adequando as necessidades de aplicações de medidas profiláticas à população;
- Monitorar e registrar a temperatura e organização dos equipamentos da rede de frio;

- Busca ativa de faltosos ao tratamento profilático.

\section{CONCLUSÃO}

Os fenômenos epidêmicos de raiva humana suscitaram em 2004 e 2005 processos de trabalho de equipes de enfermagem em três municípios do estado brasileiro do Pará, ou seja, equipes norteadas pela finalidade de evitar o aumento do número de óbitos desenvolveram medidas profiláticas específicas para combater este evento epidêmico.

A agilidade das ações de enfermagem procura se adequar às transformações epidemiológicas iminentes, e assim os processos de trabalho do enfermeiro pedem raciocínio crítico $^{(18)}$, isto é, nesta situação o enfermeiro deve ser capaz de fazer observações relevantes, reconhecer os problemas de saúde, desenvolver soluções apropriadas e avaliar os resultados destas soluções.

Na presente pesquisa de cunho Qualitativo foram analisadas as narrativas sobre os processos de trabalho de enfermeiros durante os surtos de raiva humana. A articulação e a integração dos processos de trabalho do enfermeiro, assistência, administração e ensino, foram essenciais para a realização de ações de prevenção em localidades rurais e de difícil acesso.

A análise do processo de trabalho de enfermeiros durante uma epidemia é importante para entender como é possível agir perante uma situação repentinamente instalada Que reQuer a elaboração de estratégias Que minimizem os sofrimentos dos afligidos. Para tanto, os enfermeiros precisarão compreender as relações e as necessidades das equipes de saúde para elaborar processos de trabalho Que atendam as dificuldades de grupos sociais Que procuram o serviço e Que, neste sentido, é importante atentar para as diferenças sócio-culturais.

\section{REFERÊNCIAS}

I. Bezerra PM. Surtos de raiva humana no Pará. Estudo das representações do fenômeno epidêmico [dissertação]. Belém: Universidade Federal Pará; 2008.

2. Ministério da Saúde (BR). Secretaria de Vigilância em Saúde, Departamento de Vigilância Epidemiológica. Guia de vigilância epidemiológica. Brasília: Ministério da Saúde; 2005.

3. Schneider MC, Santos-Burgoa C. Algunas consideraciones sobre la rabia humana transmitida por murcielago. Salud Publica México 1995; 37(4): 354-62.

4. Bezerra PM. Anthoropological study of rabies outbreak in the city of Portel (PA/Amazônia/Brazil): Conceptions and representation of the illness for the family of the victims. Reunión Internacional de Rabia en las Américas XVII, 2006, Out 16 19. Brasília (DF). Brasília: Reunião Internacional de Raiva nas Américas; 2006.

5. Rocha SMM, Almeida MCP. O processo de trabalho da enfermagem em saúde coletiva e a interdisciplinaridade. Rev Latino-am Enfermagem 2000; 8(6): 96-101.

6. Peduzzi M, Anselmi, ML. O processo de trabalho de enfermagem: a cisão entre planejamento e execução do cuidado. Rev Bras Enferm 2002; 55(4): 392-8.

7. Sanna MC. Os processos de trabalho em enfermagem. Rev Bras Enferm 2007; 60(2): 221 -4.

8. Fracolli LA, Granja GF. A utilização da categoria processo de trabalho pela enfermagem brasileira: uma análise bibliográfica. Rev Esc Enferm USP 2005; 39(esp): 597-602.

9. Felli $\mathrm{V}$, Peduzzi M. O trabalho gerencial em enfermagem. In: Kurcgant P, coordenadora. Gerenciamento em enfermagem. Rio de Janeiro: Guanabara Koogan; 2005. p. I-I 3.

10. Nogueira-Martins MCF, Bógus CM. Considerações sobre a metodologia eualitativa como recurso para o estudo das ações de humanização em saúde. Saúde Soc 2004; I3(3): 44-57.

I I. Gaskell G. Entrevistas individuais e grupais. In: Bauer MW, Gaskell G. Pesquisa Qualitativa com texto: Imagem e Som: um manual prático. Petrópolis: Vozes; 2004. p. 64-89.

12. Jovcheloovitch S, Bauer MW. Entrevista narrativa. In: Bauer MW, Gaskell G. Pesquisa Qualitativa com texto: Imagem e Som: um manual prático. Petrópolis: Vozes; 2004. p. 90-II3.

13. Lira, GV, Catrib, AMF, Nations, MK. A narrativa na pesquisa social em saúde: perspectiva e método. Rev Bras Prom Saúde 2003; 16: 59-66.

14. Barbosa MA, Medeiros M, Prado MA, Bachion MM, Brasil VV. 
Reflexões sobre o trabalho do enfermeiro em saúde coletiva. Rev Eletrônica Enferm 2004; 6(1): 9-15.

15. Egry EY. Saúde Coletiva. Construindo um novo modelo em enfermagem. São Paulo: Ícone Editora; 1996.

16. Santos AG, Sanna MC. A participação da enfermeira na campanha de erradicação da varíola no estado de São Paulo no período 1968-1973. Esc Anna Nery Rev Enferm 2006; 10(3):
470-7.

17. Almeida MCP, Rocha JSY. O saber da enfermagem e sua dimensão prática. São Paulo: Cortez; 1986.

18. Potter PA. O raciocínio crítico e o julgamento de enfermagem. In: Potter, PA, Perry, AGP. Fundamentos de Enfermagem: conceitos, processo e práticas. $4^{\text {a }}$ ed. Rio de Janeiro: Editora Guanabara Koogan; 1999. p. 90-8. 